ARTICLE

https://doi.org/10.1038/s41467-019-13701-5

\title{
Palladium-catalyzed Suzuki-Miyaura coupling of thioureas or thioamides
}

\author{
Shaoyu Mai (1] ${ }^{1}$, Wendong $\mathrm{Li}^{1}$, Xue $\mathrm{Li}^{1}$, Yingwei Zhao ${ }^{1}$ \& Qiuling Song (1) ${ }^{1,2 \star ~}$
}

Cross-coupling reactions involving metal carbene intermediates play an increasingly important role in $\mathrm{C}-\mathrm{C}$ bond formation. Expanding the carbene precursors to a broader range of starting materials and more diverse products is an ongoing challenge in synthetic organic chemistry. Herein, we report a Suzuki-Miyaura coupling reaction of in situ-generated $\mathrm{Pd}$-carbene complexes via desulfurization of thioureas or thioamides. This strategy enables the preparation of a broad array of substituted amidinium salts and unsymmetrical diaryl ketones. The reaction is readily scalable, compatible with bromo groups on aromatic rings, tolerant to moisture and air and has a broad substrate scope. Furthermore, a single crystal structure of $\mathrm{Pd}$-diaminocarbene complex is obtained and proven to be the key intermediate in both catalytic and stoichiometric reactions. Preliminary mechanistic studies demonstrate the dual role of the silver salt as a desulfurating reagent assisting the elimination of sulfur and as oxidant facilitating the $\mathrm{Pd}^{\prime \prime} / \mathrm{Pd}^{0} / \mathrm{Pd}^{\prime l}$ catalytic cycle.

\footnotetext{
${ }^{1}$ Institute of Next Generation Matter Transformation, College of Chemical Engineering and College of Material Sciences Engineering at Huaqiao University, 668 Jimei Boulevard, Xiamen, Fujian 361021, China. ${ }^{2}$ Key Laboratory of Molecule Synthesis and Function Discovery, Fujian Province University, College of Chemistry at Fuzhou University, Fuzhou, Fujian 350108, China. *email: qsong@hqu.edu.cn
} 
$\mathrm{n}$ the past decade, the transition-metal-catalyzed carbene coupling reactions have emerged as one of the most powerful and reliable methods for carbon-carbon bond construction $^{1-15}$. In most of these coupling reactions, diazo compounds were frequently employed to serve as very useful precursors for metal carbene generation, and many elegant transformations have been developed with diazo compounds, as a consequence, more and more chemists have been attracted to devote to this field ${ }^{10-13}$. In spite of the great advance and importance of diazo compounds in carbene coupling reactions, the discovery and development of carbene synthons which possess versatile reactivity and are stable, as well as convenient to prepare is still highly challenging ${ }^{14,15}$. In 2007 , Barluenga et al. reported the first palladium-catalyzed carbene cross-coupling with tosylhydrazones (the precursors for in situ generated diazo compounds $)^{2}$. Subsequently, they demonstrated a powerful reductive coupling of tosylhydrazones with boronic acids in the absence of a metal catalyst ${ }^{3}$. In addition, the allenyl ketones ${ }^{5}$, eneyne-ketones $^{6}$, alkynes ${ }^{7}$, cyclopropenes ${ }^{8}$ along with chromium $(0)$ Fischer carbene complexes ${ }^{9}$, have been proven as effective metal carbene precursors in cross-couplings by Wang and co-workers, which have prominently enriched the toolboxes of synthetic chemists (Fig. 1a). In 1993, Kuhn and co-workers ${ }^{16-18}$ reported an efficient method for the synthesis of metal $\mathrm{N}$-heterocyclic carbene (NHC) complexes: it involves the synthesis of NHC complexes via desulfurization of imidazole-derived thioureas in the first step, and subsequent coordination to corresponding metal salts. Such desulfurization of thioureas needs stoichiometric amounts of potassium or sodium as desulfurating reagents via the removal of $\mathrm{K}_{2} \mathrm{~S}$ or $\mathrm{Na}_{2} \mathrm{~S}$. However, the stoichiometric alkali metals, harsh reaction conditions and limited scope of acyclic thioureas restricted their application in organic synthesis, especially in metal-catalyzed organic reactions. In addition, Yang et al. have recently demonstrated that thioureas can serve as ligands to a variety of different transition-metal-catalyzed reactions, because of the strong coordinative and adsorptive properties of the sulfur atom, and they have also found their application in the total synthesis of natural products ${ }^{19}$. In 2005, Fürstner et al. reported the elegant synthesis of metal-diaminocarbene complexes $\mathrm{C}$ (from thioureas) or metal-monoaminocarbene complexes $\mathbf{C}^{\prime}$ (from thioamides) by oxidative addition of electron-rich metal centers (e.g., $\mathrm{Pd}^{0}, \mathrm{Ni}^{0}$ ) into the Vilsmeier-type salts $\mathbf{B}$, which were

a Transition-metal-catalyzed cross-couplings via carbene migratory insertion

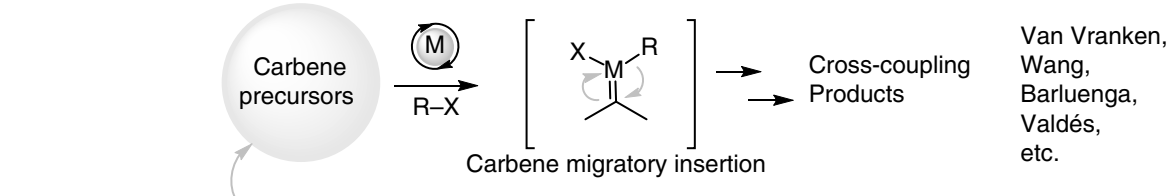

b Our concept: via desulfurization?

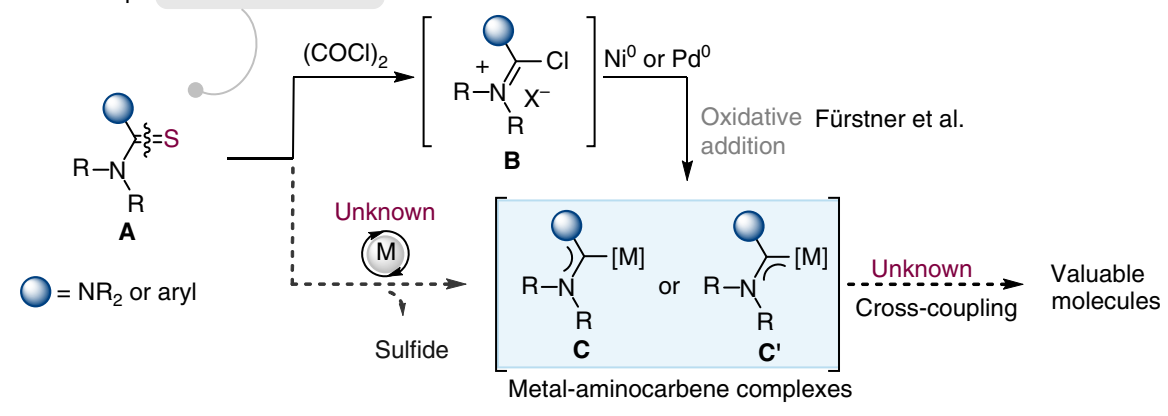

C Hypothesis for reaction mechanism: cross-couplings via carbene reductive elimination

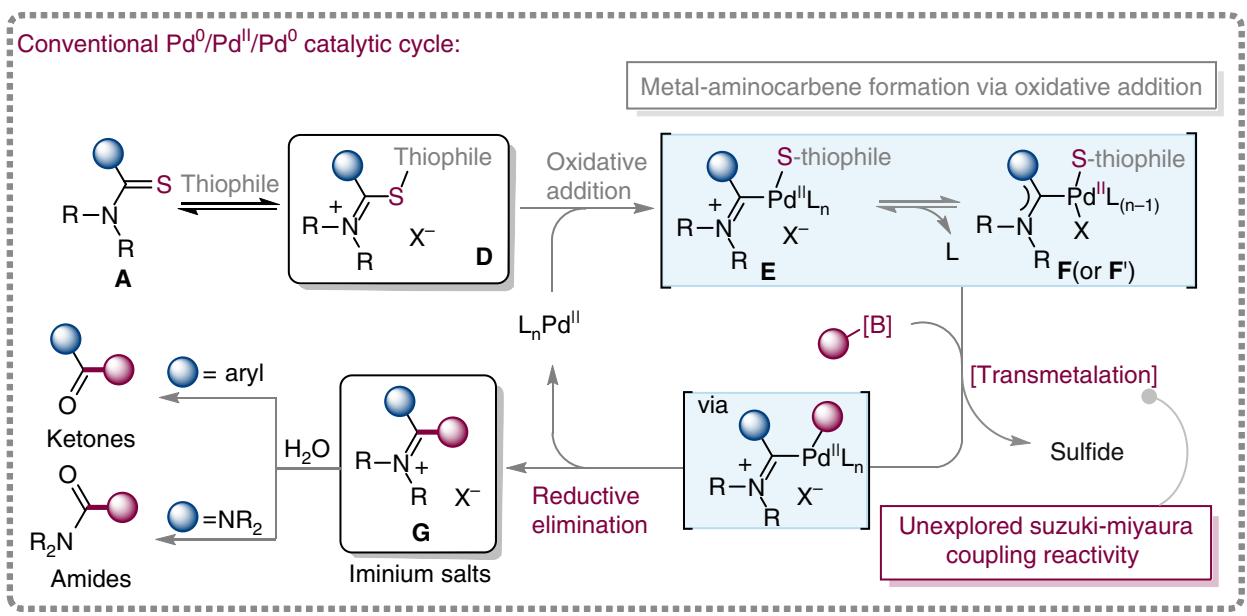

Fig. 1 Direct desulfurization for the generation of carbenes. a Transition-metal-catalyzed carbene coupling reactions by carbene migratory insertion. $M=$ metal. $\mathbf{b}$ Our concept for the catalytical generation of metal-aminocarbene from thioamide derivatives $\mathbf{A}$ and its crossing coupling reactions. $\mathbf{c}$ Hypothesis of mechanism for desulfurative Suzuki-Miyaura coupling reaction based on $\mathrm{Pd} / / \mathrm{Pd}^{\prime \prime} / \mathrm{Pd}^{0}$ catalytic cycle by carbene reductive elimination. $\mathrm{X}^{-}=$anion; $\mathrm{L}=$ Ligand. 
prepared from thioamide derivatives $\mathbf{A}$ and oxalyl chloride (Fig. 1b) ${ }^{20}$. For the reactivity of metal-aminocarbene complexes, Grushin, Yates and Cavell demonstrated that the alkyl/aryl/acylcarbene reductive elimination from imidazole-derived $\mathrm{Pd}^{\mathrm{II}}$ heterocylic carbene complexes, as the side reaction in metal-NHC system, could lead to catalyst deactivation along with undesired carbon-carbon bond formation ${ }^{21,22}$, indicating that the reaction of metal-aminocarbene and its ligand prefer carbene reductive elimination to carbene migratory insertion.

In continuation of our work on the reactivity of the thioamidederived substrates ${ }^{23,24}$ and inspired by Kuhn's NHCs synthesis, we are intrigued by the possibility of the thioamide derivatives (thioureas can be regarded as two parts of thioamide) as metal carbene precursors. The use of thioamide derivatives $\mathbf{A}$ for the catalytical generation of metal-aminocarbenes through the elimination of sulfide is particularly appealing and is expected to offer great opportunities, especially when it leads to unconventional reaction mechanism and unique retrosynthetic relationships (Fig. 1b). To elaborate the feasibility of our plan, we propose a plausible mechanism depicted in Fig. $1 \mathrm{c}$, which involves $\mathrm{Pd}^{0} / \mathrm{Pd}^{\mathrm{II}} /$ $\mathrm{Pd}^{0}$ catalytic cycle. Generally, the reversible intermediate $\mathbf{D}$ can be easily generated from thioamide $\mathbf{A}$ as a result of the coordination of thiophile (or thiophilic auxiliary) ${ }^{25-29}$, which leads to oxidative addition of the C-S bond ${ }^{30-35}$ in the presence of active $\mathrm{L}_{\mathrm{n}} \mathrm{Pd}^{0}$, affording the formal sulfur-containing metal-aminocarbene intermediate in equilibrium between the cationic form $\mathbf{E}$ and the neutral form $\mathbf{F}$ or $\mathbf{F}^{\prime}$ (not shown in Fig. 1c) ${ }^{20}$. The development of a catalytic version of this type of reactions from thioamide derivatives remains a formidable challenge, probably due to the high-energy barrier in desulfurization process, the poor compatibility of desulfurating reagents with substrates and the difficulty in finding a suitable condition and appropriate metal which can not only capture the in situ-generated carbene species but also accomplish the catalytic crossing-coupling cycle, meanwhile, the metal catalyst can't be poisoned by sulfur species. Given the commercial availability, stability, and nontoxicity of organoboron reagents, transition-metal catalyzed Suzuki-Miyaura coupling (SMC) will be an ideal choice for achieving the aforementioned catalytic cycle ${ }^{36-44}$. Thus, the coupling of the
Pd-aminocarbene complex with organoboron ${ }^{\mathrm{I}}$ compound can in principle produce the iminium salt intermediate $\mathbf{G}$ via reductive elimination, which will set the stage for the preparation of a broad array of substituted amidinium salts (from thioureas) and unsymmetric ketones (from thioamides). Remarkably, the amidinium salts are prevalent in many functional molecules or materials and bioactive molecules ${ }^{45-48}$ (Fig. 2), such as amidinium salt I (a hydrogen-bond donor to activate electron-deficient quinones and a catalyst in a quinone-mediated model synthetic transformation) ${ }^{45}$, amidinium salt II (antistatic agent) ${ }^{46}$, III (alkaline-stable benzimidazolium in high-performance hydroxide conducting membranes) ${ }^{47}$ and amidinium salt IV (antifungal agent $)^{48}$. Moreover, amidinium salts are a well-known subclass of ionic liquids (ILs) ${ }^{49,50}$.

Herein, we now report a successful example of the use of an in situ-generated $\mathrm{Pd}$-carbene complex through desulfurization of thioureas or thioamides to accomplish Suzuki-Miyaura coupling reaction to afford a broad array of substituted amidinium salts or valuable diaryl ketones.

\section{Results}

Synthetic methodology development. Firstly, after detecting the formation of amide phenyl(piperidin-1-yl)methanone (3) in 15\% yield (Table 1, entry 2 ) by using di(piperidin-1-yl)methanethione (1a) and phenyl boronic acid (2a) as the model substrates, we next investigated the effect of Pd catalysts and found that common $\mathrm{Pd}\left(\mathrm{PPh}_{3}\right)_{2} \mathrm{Cl}_{2}$ was the best choice (Table 1, entries 1-5). According to the related reports, the desulfurization of thioamide derivatives were efficiently performed with $\mathrm{Ag}_{2} \mathrm{CO}_{3}{ }^{25}$, $\mathrm{CuSO}_{4} \cdot 5 \mathrm{H}_{2} \mathrm{O}^{26}, \mathrm{CoCl}_{2} \cdot 6 \mathrm{H}_{2} \mathrm{O}^{27}$, and $\mathrm{PhI}(\mathrm{OAc})_{2}{ }^{28}$ by the formation of $\mathrm{Ag}_{2} \mathrm{~S}, \mathrm{CuS}, \mathrm{CoS}$ and elemental sulfur respectively. Screening of common desulfurating reagents showed that $\mathrm{Ag}_{2} \mathrm{CO}_{3}$ exhibited best activity (Table 1, entries 5-9). To facilitate transmetallation of phenyl boronic acid, a series of additional bases was also studied and $\mathrm{Na}_{2} \mathrm{CO}_{3}$ was the optimal one (entries 11-13). The amount of Pd catalyst as well as the silver salt loading and base usage highly affected the efficiency of this transformation. When submitting $\mathbf{1 a}$ and $\mathbf{2 a}$ along with $10 \mathrm{~mol} \%$ of $\mathrm{Pd}$

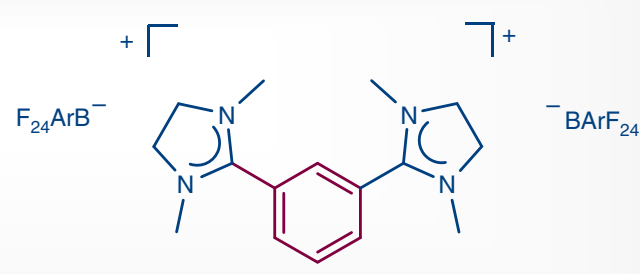

I, Hydrogen-bond donor

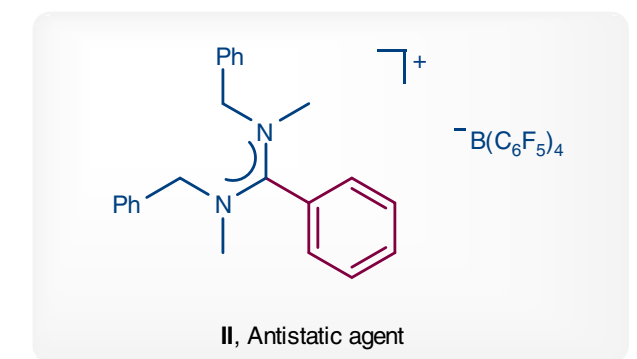

II, Antistatic agent

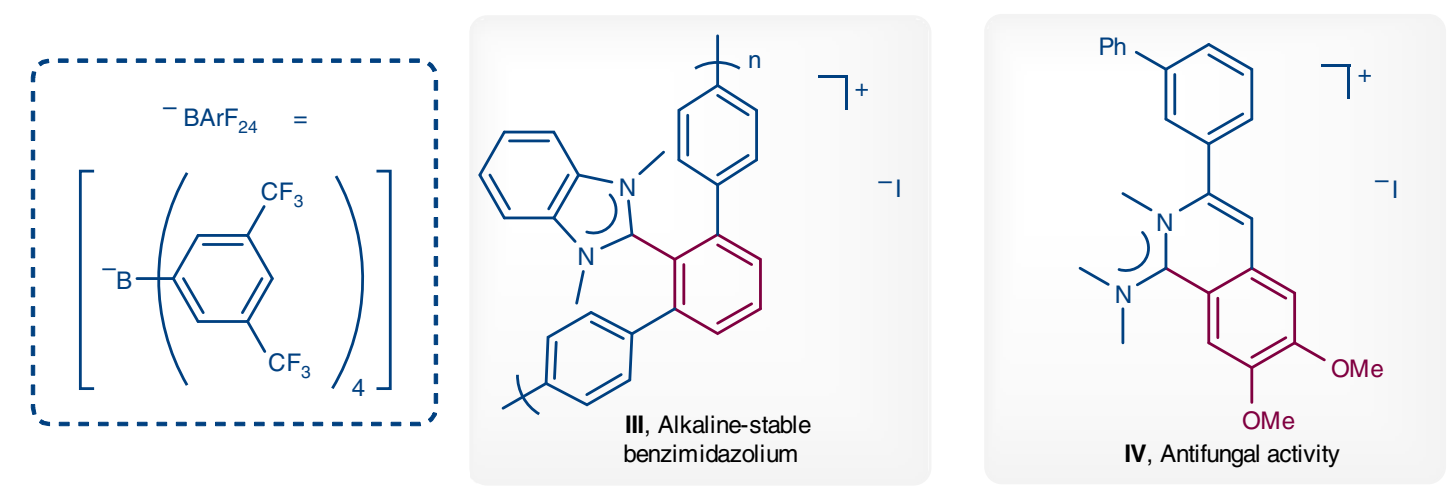

Fig. 2 Selected compounds containing amidinium salt unit. The significance of amidinium salts I-IV. 
Table 1 Optimization of reaction conditions.

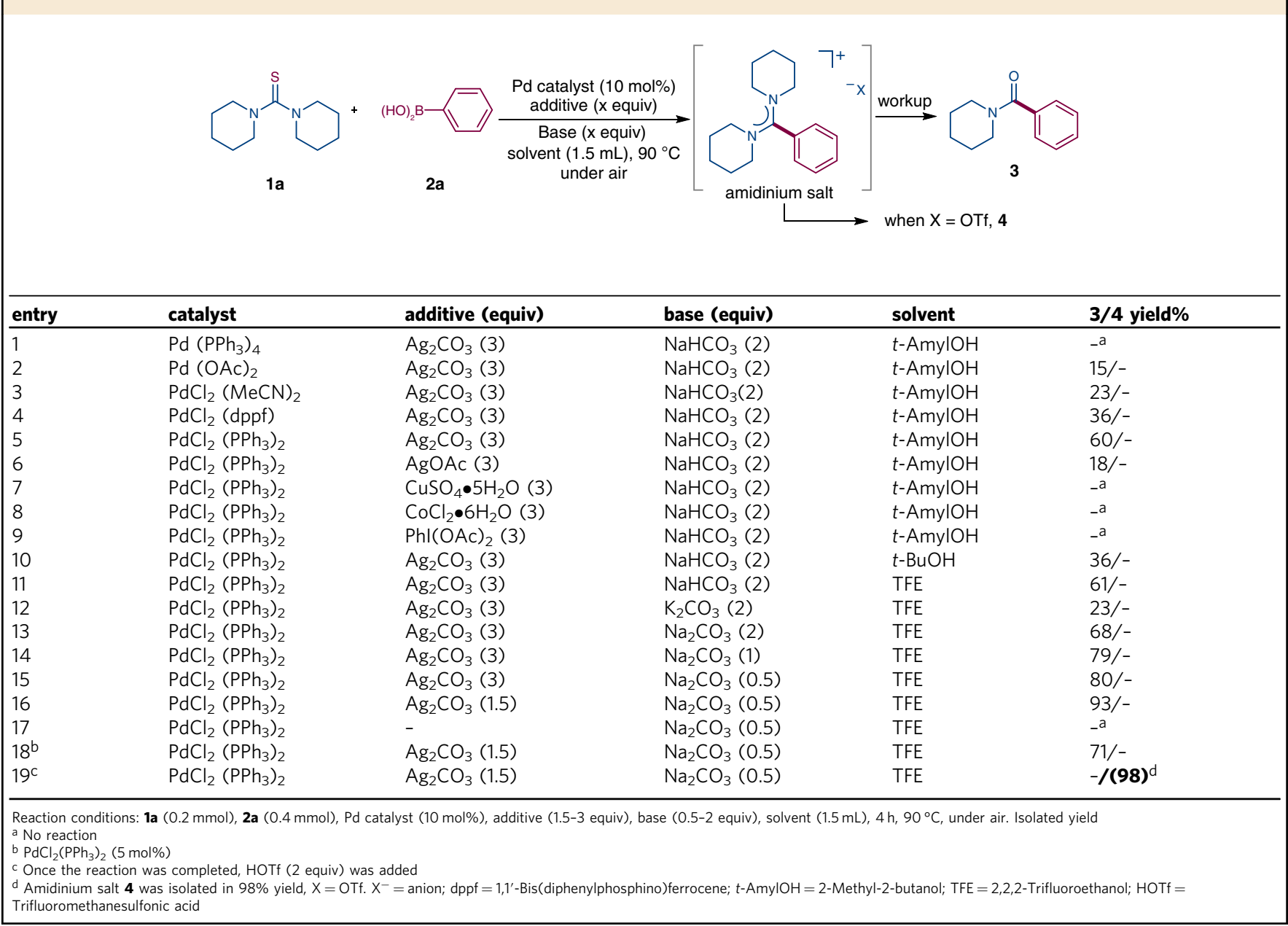

$\left(\mathrm{PPh}_{3}\right)_{2} \mathrm{Cl}_{2}$ in trifluoroethanol (TFE, without dehydration) under air atmosphere with 1.5 equivalents of $\mathrm{Ag}_{2} \mathrm{CO}_{3}$, a 93\% yield of the amide phenyl(piperidin-1-yl)methanone (3) could be obtained (Table 1, entry 16). Silver salt was essential for the success of this reaction (Table 1, entry 17). Based on our proposed mechanism, the hydrolysis of intermediate $\mathbf{G}$ can provide amide using thiourea as the substrate (Fig. 1c). To capture the intermediate $\mathbf{G}$, we tried to add two equivalents of HOTf into the reaction system without workup. Fortunately, we found the amidinium salt 4 with OTf anion was obtained in $98 \%$ yield (Table 1, entry 19) and its structure has been unambiguously confirmed by X-ray crystallographic analysis (Table 2, CCDC 1895265).

Substrate scope with respect to amidinium salts. With the optimized reaction conditions (Table 1, entry 19) in hand, we investigated the substrate scope of the construction of amidinium salts first (Table 2). In general, boronic acids bearing both electron-donating (e.g., - Me, -iPr, -OEt, - Ph) and electronwithdrawing groups (e.g., $-\mathrm{F},-\mathrm{Cl},-\mathrm{CN}$ ) on the aromatic rings could react smoothly to produce amidinium salts in good yields (4-12, 18-19).

It is noteworthy, yet very unusual in palladium chemistry, that bromo-substituted boronic acids were tolerated well under our conditions (13 and 20), and this provides an extremely important choice for cross-coupling reactions and makes the further structural elaboration feasible. Significantly, boronic acids bearing versatile functional groups, such as $-\mathrm{OH},-\mathrm{CHO},-\mathrm{Ac}$, and $-\mathrm{COOEt}$ are competent reaction partners as well $(\mathbf{8}, \mathbf{1 5}-\mathbf{1 7})$. Polyphenylene species, like naphthalene and 9,9-dimethyl-9H-fluorene were also amenable motifs (21-22). Heteroaromatic substrates, such as unprotected indole and dibenzo[b,d]thiophene were successfully converted to the corresponding products in $73-76 \%$ (23 and 24). Next, we investigated the effect of substituents on thioureas. Good results were obtained with di(pyrrolidin-1-yl)methanethione and 1,1,3,3-tetramethyl-thiourea (25 and 26). Expanding the scope to the cyclic thioureas was also effective, affording five-, six-, and seven-membered amidinium salts in $86 \%, 76 \%$, and $90 \%$ yield, respectively (27-29). Notably, ortho substituted boronic acids also exhibited acceptable reactivity, although corresponding amidinium salts were obtained in lower yields (30 and 31). Importantly, unsymmetric thioureas were also good candidates in this method, featuring the positive ion delocalization in $\mathrm{N}-\mathrm{C}-\mathrm{N}$ triple atom (32 and 33). Considering the importance of carbazole moiety ${ }^{51}$ (organic light emitting diodes, OLEDs), Amoxapine ${ }^{52}$ (antidepressant) and Cytisine ${ }^{53}$ within optoelectronic materials, drugs, or natural products, we synthesized the structurally complex amidinium salts in satisfactory yield (34-36) using corresponding substrates bearing thiourea units. Moreover, estrone-derived arylboronic acid pinacol ester could also smoothly convert to amidinium salt 37 in $92 \%$ yield, indicating that our protocol enables a practical late-stage modification in medicinal chemistry.

Substrate scope with respect to diaryl ketones. The existence of $\mathrm{Pd}^{\mathrm{II}}$-monoaminocarbene complexes ${ }^{20}$ and the success of above reactions prompted us to expand this catalytic system to more general thioamide-containing substrates. Thioamides can be easily obtained by different functional group transformation, 
Table 2 Substrate scopes with respect to the construction of amidinium salts ${ }^{a}$.
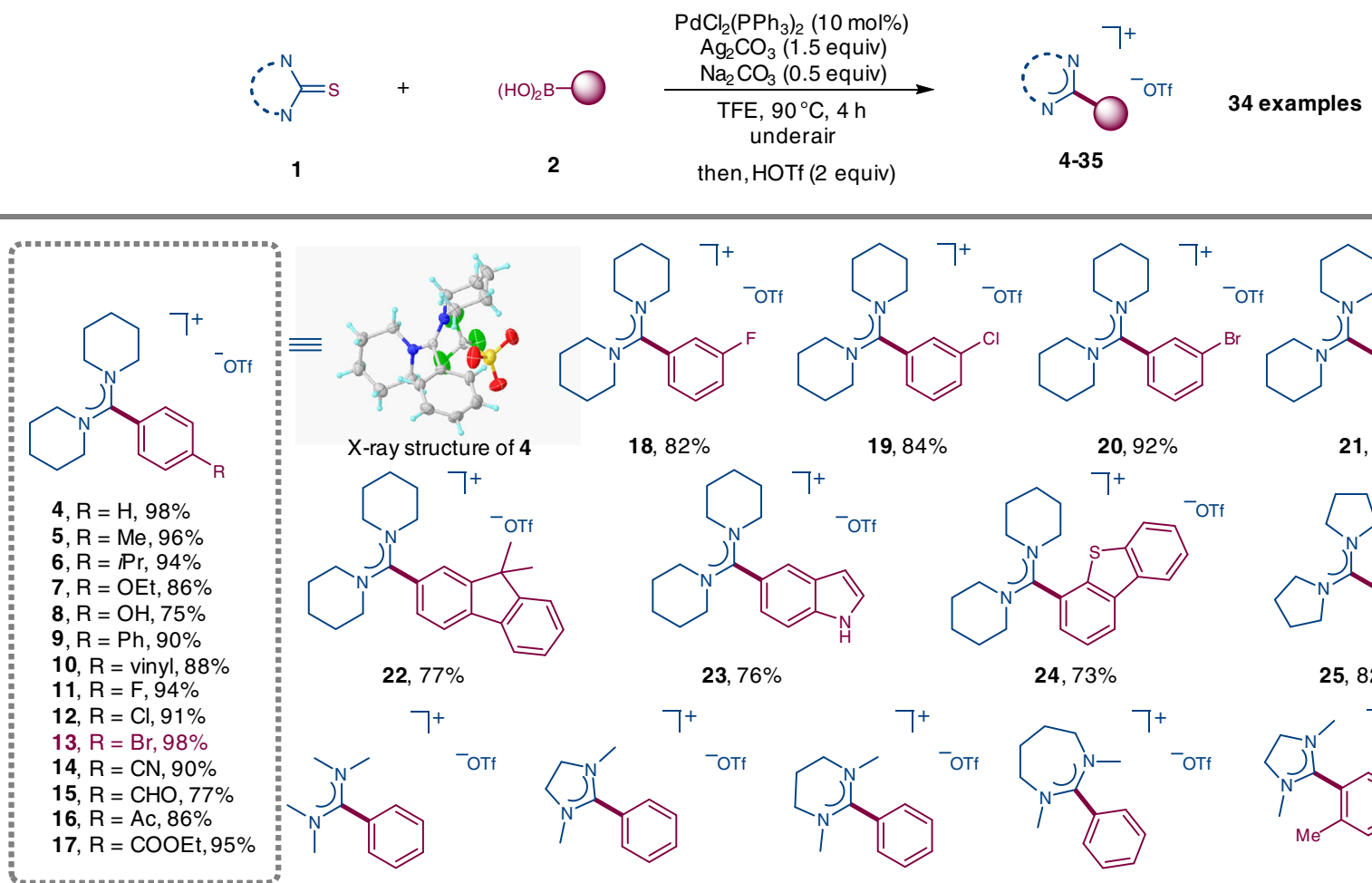

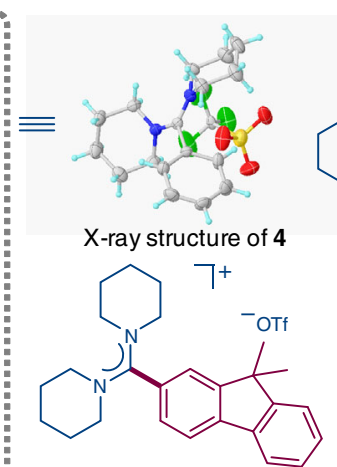

22, $77 \%$

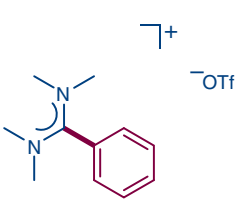

26, $88 \%$<smiles></smiles>

$18,82 \%$<smiles>[I-]C1CCCCN1C(c1ccc2[nH]ccc2c1)N1CCCCC1</smiles>

23, $76 \%$<smiles>FC(F)(F)c1cccc(Cl)c1</smiles>

$19,84 \%$

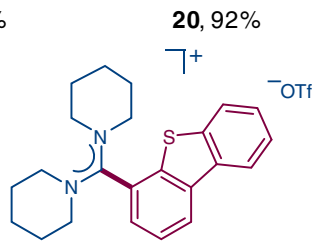

$24,73 \%$

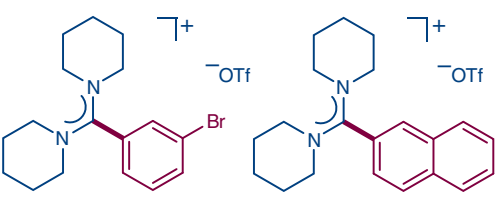

$21,88 \%$<smiles>OC1(O[I-])CCCN1C(c1ccccc1)N1CCCC1</smiles>

$25,82 \%$<smiles>Cc1ccccc1C1N(C)CCN1C</smiles>

$30,44 \%$

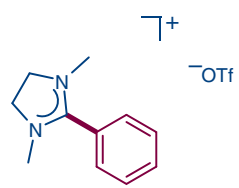

$27,86 \%$

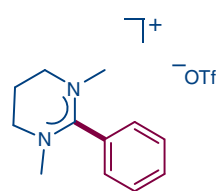

28, $76 \%$

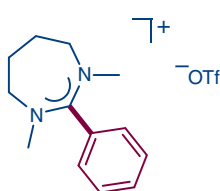

29, $90 \%$<smiles>CCc1ccccc1C1N(C)CCN1C[I+]</smiles>

31, $32 \%$

32, $66 \%$

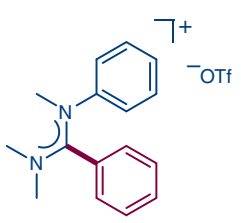

$33,93 \%$

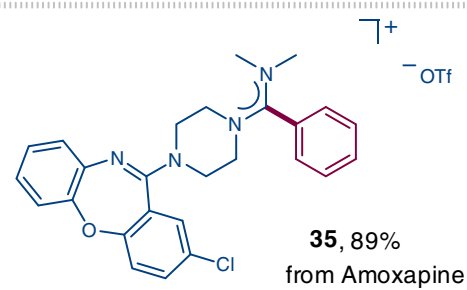

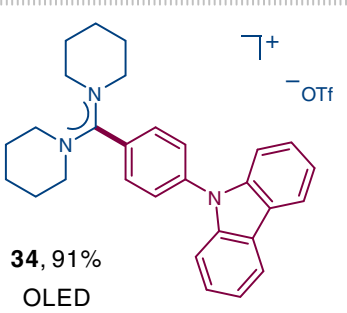

OLED

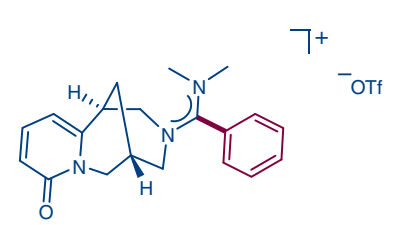

36, $72 \%$

from Cytisine
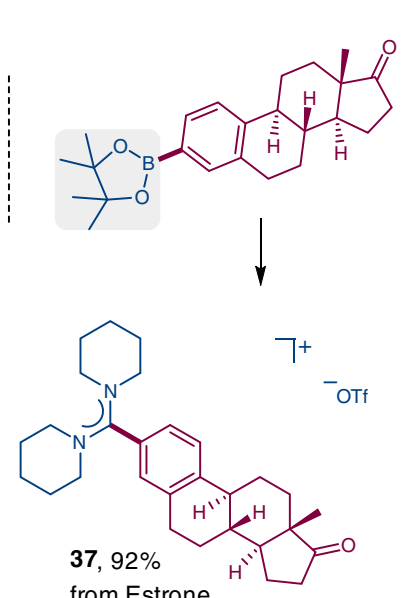

aReactions were performed with $\mathbf{1}\left(0.2 \mathrm{mmol}, 1\right.$ equiv), $\mathbf{2}\left(0.4 \mathrm{mmol}, 2\right.$ equiv), and $\mathrm{PdCl}_{2}\left(\mathrm{PPh}_{3}\right)_{2}(10 \mathrm{~mol} \%), \mathrm{Ag}_{2} \mathrm{CO}_{3}\left(1.5\right.$ equiv) and $\mathrm{Na}_{2} \mathrm{CO}_{3}\left(0.5\right.$ equiv) in $\mathrm{TFE}(1.5 \mathrm{~mL})$ at $90{ }^{\circ} \mathrm{C}$ for $4 \mathrm{~h}$ under air. Then, HOTf (2 equiv) was added after the reaction. Isolated yields

meanwhile, they also serve as versatile building blocks to provide valuable compounds ${ }^{54}$. Conventionally, Lawesson's reagent and its analogues are employed to the synthesis of thioamides, starting from aryl amides, aryl carboxylic acids, and nitriles 55 . Willgerodt-Kindler reaction is another alternative means to access thioamides, starting from different types of starting materials such as aryl aldehydes, aryl alkyl ketones, aryl amides, and aryl acetic acids in one step 56,57 . It means that these common compounds can conveniently be used to prepare diaryl ketones in two steps with our method, which can enlarge the accessible chemical space. Although different strategies have been developed, alternative syntheses of diaryl ketones, which can commendably deal with the problem of chemoselectivity and poor functional group compatibility ${ }^{58,59}$, are still highly desirable and a pursued goal in the synthetic field ${ }^{39,41}$. Our primary studies on the reaction of thioamide with phenyl boronic acid (2a) also gave positive results through employing the $\mathrm{Cu}(\mathrm{OAc})_{2} \bullet \mathrm{H}_{2} \mathrm{O}$ as additive instead of $\mathrm{Ag}_{2} \mathrm{CO}_{3}$ (Table 3). Using $7.5 \mathrm{~mol} \%$ $\mathrm{PdCl}_{2}\left(\mathrm{PPh}_{3}\right)_{2}$, thioamides smoothly reacted with aryl boronic acids to afford both symmetric and unsymmetric diaryl ketones in medium to excellent yields (Table 3, 38-89). This transformation exhibited an excellent functional group tolerance. In addition to alkyl groups, halo, vinyl, ketone, ester, cyano, nitro, hydroxyl groups, complex structure (adapalene), as well as 


\section{Table 3 Substrate scope of simple and efficient synthesis of diaryl ketones. ${ }^{\text {a }}$}
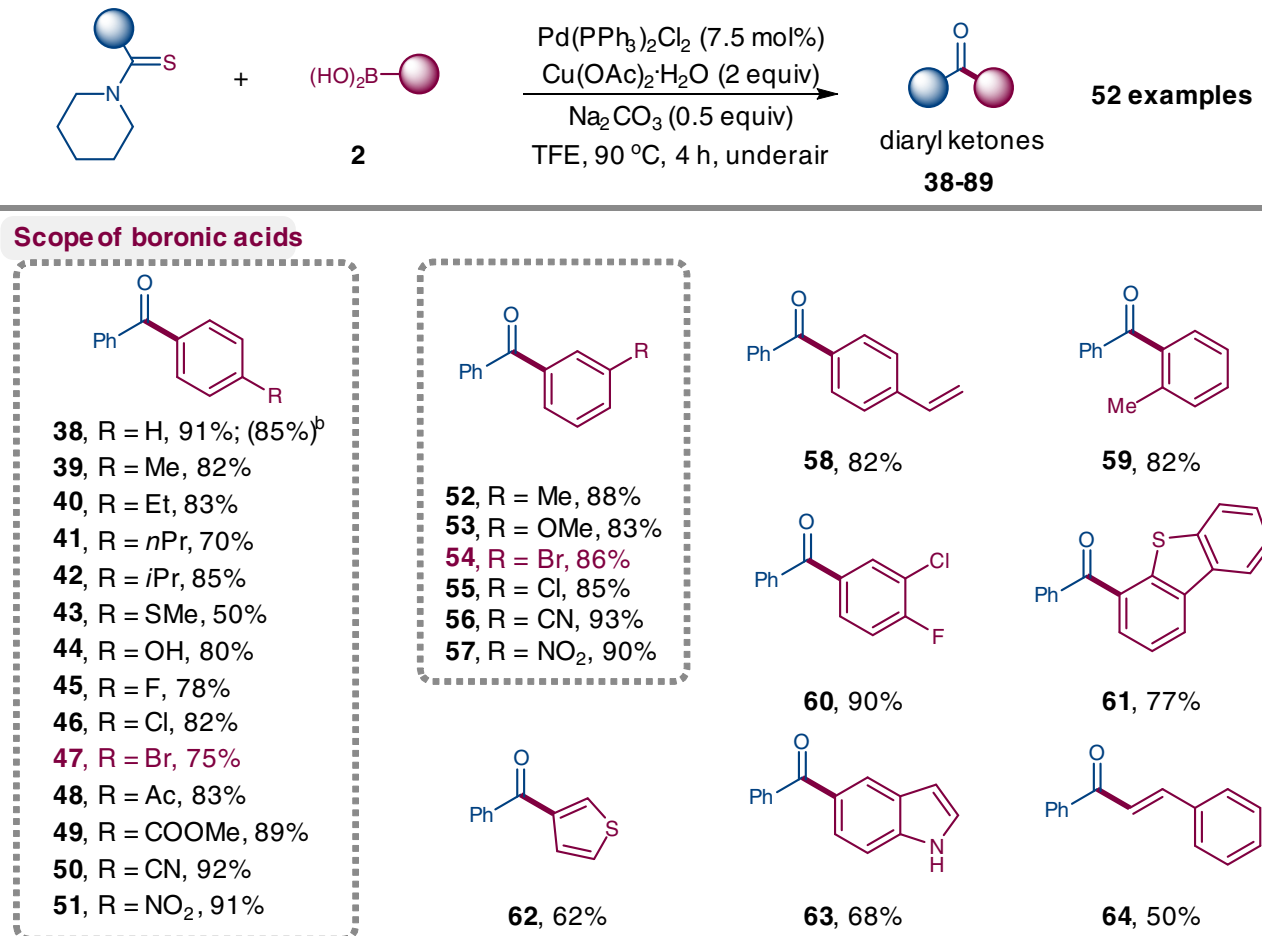

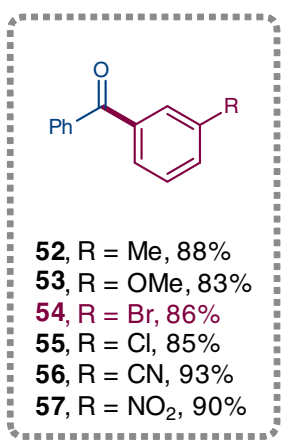<smiles>C=Cc1ccc(C(=O)c2ccccc2)cc1</smiles>

$58,82 \%$<smiles>O=C(c1ccccc1)c1ccc(F)c(Cl)c1</smiles>

60, $90 \%$<smiles>O=C(c1ccccc1)c1ccsc1</smiles>

62, $62 \%$<smiles>O=C(c1ccccc1)c1ccc2[nH]ccc2c1</smiles>

63, $68 \%$<smiles>Cc1ccccc1C(=O)c1ccccc1</smiles>

$59,82 \%$<smiles>O=C(c1ccccc1)c1cccc2c1sc1ccccc12</smiles>

$61,77 \%$<smiles>O=C(/C=C/c1ccccc1)c1ccccc1</smiles>

$64,50 \%$

\section{Scope of thioamides}

$65, \mathrm{R}=\mathrm{Me}, 87 \%$
$66, \mathrm{R}=\mathrm{tBu}, 85 \%$
$67, \mathrm{R}=\mathrm{F}, 70 \%$
$68, \mathrm{R}=\mathrm{Cl}, 86 \%$
$69, \mathrm{R}=\mathrm{Br}, 79 \%$
$70, \mathrm{R}=\mathrm{CF}_{3}, 51 \%$
$71, \mathrm{R}=\mathrm{NO}_{2}, 68 \%$
$72, \mathrm{R}=\mathrm{NPh}_{2}, 88 \%$

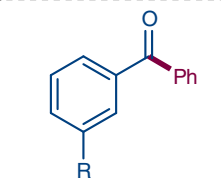

73, $\mathrm{R}=\mathrm{Me}, 89 \%$

74, $\mathrm{R}=\mathrm{Cl}, 90 \%$

$75, \mathrm{R}=\mathrm{Br}, 98 \%$

76, $\mathrm{R}=\mathrm{NO}_{2}, 71 \%$<smiles>C=C(C=N)C(=O)c1ccccc1</smiles>

$83,60 \%$<smiles>O=C(c1ccccc1)c1ccccc1Br</smiles><smiles>Cc1cc(C(=O)c2ccccc2)cc([N+](=O)[O-])c1</smiles>

$\mathbf{8 0}, 81 \%$<smiles>O=C(c1ccccc1)c1cc2ccccc2s1</smiles>

$81,84 \%$<smiles>O=C(c1ccccc1)c1ccnc2ccccc12</smiles>

$85,61 \%$<smiles>O=C(c1ccccc1)c1cccc2cccnc12</smiles>

$\mathbf{8 6}, 55 \%$
Synthetic applications<smiles>C=CC=C(C)c1ccc2cc(C(=O)c3ccccc3)ccc2c1</smiles>

$87,80 \%$

(from adapalene, ..... antiacnedrugs<smiles>COc1cc(C(=O)c2ccc3[nH]c(-c4ncco4)cc3c2)cc(OC)c1OC</smiles>

88, $63 \%$

Potentantiproliferativeagen<smiles>CCCCOC(=O)OCCCCCOc1ccc(C(=O)c2ccc(Cl)cc2)cc1</smiles>

a lipid-lowering drug

aReactions were performed with thioamide $\left(0.2 \mathrm{mmol}, 1.0\right.$ equiv), $2\left(0.4 \mathrm{mmol}, 2\right.$ equiv), and $\mathrm{PdCl}_{2}\left(\mathrm{PPh}_{3}\right)_{2}(7.5 \mathrm{~mol} \%), \mathrm{Cu}(\mathrm{OAc})_{2} \bullet \mathrm{H}_{2} \mathrm{O}(2 \mathrm{equiv})$ and $\mathrm{Na}_{2} \mathrm{CO}{ }_{3}(0.5 \mathrm{equiv})$ in TFE $(1.5 \mathrm{~mL})$ at $90{ }^{\circ} \mathrm{C}$ for $4 \mathrm{~h}$ under air. Isolated yields

UUsing $\mathrm{PdCl}_{2}\left(\mathrm{PPh}_{3}\right)_{2}(10 \mathrm{~mol} \%)$ and $\mathrm{Ag}_{2} \mathrm{CO}_{3}(1.5$ equiv $)$ 

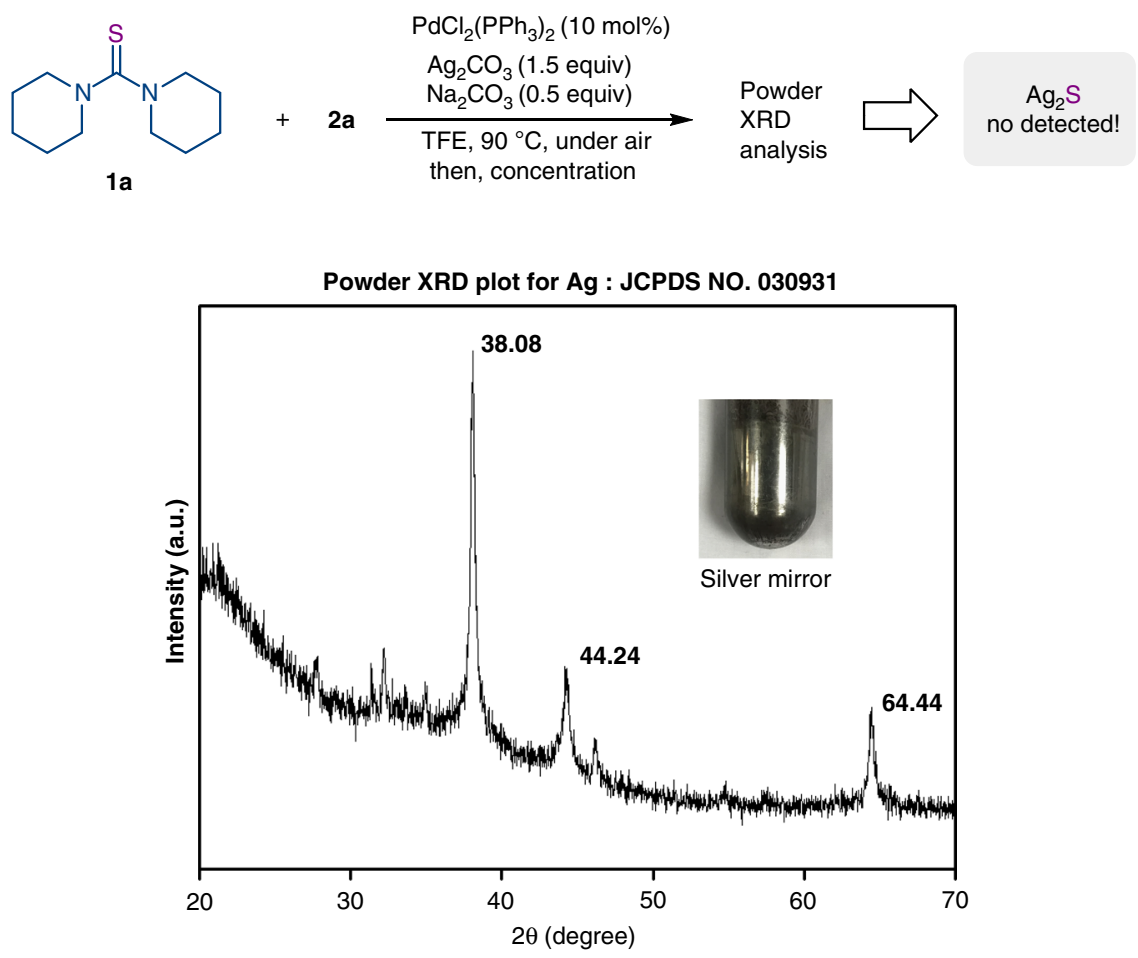

Fig. 3 Powder XRD analysis of the reaction mixture. (inset) The photo of the silver mirror.

heterocycles such as indole, thiophene, pyridine and quinolone were all tolerated well. Again, bromine substituted substrates were not impeded by our catalytic protocol, thus indicating that the activation of thiourea or thioamide was prior to the oxidative addition of aryl bromide by Pd catalysis. Next, a potent antiproliferative agent ${ }^{60} \mathbf{8 8}$ was readily obtained in $63 \%$ yield from the corresponding thioamide and indolyboronic acid under the standard coupling conditions. Fenofibrate, a cholesterolmodulating drug ${ }^{61}$, could be obtained in $90 \%$ yield under similar operation (Table 3, 89).

Mechanistic investigation. On the basis of the aforementioned reaction mechanism (Fig. 1c) and relevant reports, this coupling would in principle produce one molecule of $\mathrm{Ag}_{2} \mathrm{~S}$ to finish the transmetalation with organoboron compound ${ }^{25-28}$, suggesting that the silver should not change in valence state. Remarkably, the black colored precipitate, collected after the reaction through direct concentration in vacuo, was characterized by the powder $\mathrm{XRD}$ analysis (X-ray diffraction analysis); notably, no $\mathrm{Ag}_{2} \mathrm{~S}$ (JCPDS 14-72) was detected. As can be seen from Fig. 3, it is a clear indication for the existence of elemental silver in the powder $\mathrm{X}$-ray analysis picture, which well matched the standard XRD pattern of elemental silver (JCPDS No.030931). Moreover, we also observed a silver mirror during the reaction, indicating that the Ag salt would serve as an oxidant to furnish the catalytic cycle.

To demonstrate the detailed reaction process, several control experiments were performed. When urea 90 was exposed to the standard conditions, no reaction occurred, suggesting the necessity of the unique structure of thiourea for the success of the transformation (Fig. $4 \mathrm{a}$, eq 1). In order to identify the fate of sulfur element and to intercept the possible Pd intermediates, the thiourea 1a was mixed with a stoichiometric amount of $\mathrm{PdCl}_{2}\left(\mathrm{PPh}_{3}\right)_{2}$ and 1.5 equiv of $\mathrm{Ag}_{2} \mathrm{CO}_{3}$ at $90{ }^{\circ} \mathrm{C}$ for $4 \mathrm{~h}$. Surprisingly, only in the presence of $\mathrm{Ag}_{2} \mathrm{CO}_{3}$, triphenylphosphine sulfide 91 was isolated in $51 \%$ yield ( $\mathrm{PhSPh}$ was also detected under the catalytic reaction, please see the Supplementary Fig. 4).
We speculated that the elemental sulfur might be generated during the reaction and then was captured by the triphenylphosphine (released from the Pd catalysis) (Fig. 4b, eq 2 left). Indeed, the $\mathrm{PPh}_{3}$ was readily sulfurized in TFE to triphenylphosphine sulfide 91 in $95 \%$ yield (Fig. 4b, eq 2 right).

After filtration of inorganic solids and addition of ether solvent, yellow crystal 94 was precipitated and separated, and the unique carbene structure was confirmed by X-ray crystallography (Fig. 4b). All these operations were conducted under air atmosphere. The square structure of this complex indicates it is a cis-configured $\mathrm{Pd}$ II species (CCDC 1820330). The bond lengths of Pd-C1 (2.004 $\AA$ ), C1-N1 (1.339 $\AA$ ) and C1-N2 (1.325 $)$, as well as the $\mathrm{N}-\mathrm{C}-\mathrm{N}$ angle $\left(122.8^{\circ}\right)$ are consistent with those known similar acyclic diaminocarbene-Pd complexes ${ }^{20}$, meanwhile, the two $\mathrm{C}-\mathrm{N}$ bond lengths $(1.339 \AA$ and $1.325 \AA$ ) are typical $\mathrm{C}=\mathrm{N}$ bond length, it sufficiently suggested the phenomenon of electron delocalization in N-C-N triple atom system (Fig. 4b, eq 3). Moreover, the HRMS (high resolution mass spectrometry) analysis of the mixture of the standard reaction for $30 \mathrm{~min}$ showed the distinctive $\mathrm{Pd}$ peak at $\mathrm{m} / \mathrm{z}=845.2166$, which matched the cationic form intermediate 93 (calcd mass: 845.2167). According to the control experiment (Table 1, entry 17), the Ag salt would play dual roles in this transformation: it acts as a thiophilic auxiliary for desulfurization to form metalaminocarbene complex, at the same time, it also serves as an oxidant to oxidize $\mathrm{Pd}^{0}$ to $\mathrm{Pd}^{\mathrm{II}}$ to furnish the catalytic cycle. Next, complex 94 catalyzed the Suzuki-Miyaura reaction under the standard conditions in the presence of $\mathrm{Ag}_{2} \mathrm{CO}_{3}$ delivering benzamide 3 in high yield, suggesting the plausible intermediacy of it in the catalytic cycle (Fig. 4b, eq 4). Not surprisingly, in the absence of $\mathrm{Ag}_{2} \mathrm{CO}_{3}$, there was no product 3 detected. The reaction between stoichiometric amount of complex 94 and arylboronic acid $\mathbf{2 a}$ was performed subsequently under the standard conditions (Fig. 4b, eq 5), rendering 3 in $81 \%$ yield (with $\mathrm{Ag}_{2} \mathrm{CO}_{3}$ ) or in $70 \%$ yield (without $\mathrm{Ag}_{2} \mathrm{CO}_{3}$ ), which further confirmed the possibility that complex 94 is the key intermediate in our transformation. Moreover, to get more insight into the 
a<smiles>O=C(N1CC[CH+]CC1)N1CCCCC1</smiles>

90<smiles>Oc1ccccc1</smiles>

2a
"Standard conditions" workup<smiles>O=C(c1ccccc1)N1CCCCC1</smiles>

3, Not detected

(Eq. 1)

b<smiles>S=C(N1CCCCC1)N1CCCCC1</smiles>

$\mathrm{PdCl}_{2}\left(\mathrm{PPh}_{3}\right)_{2}$ (1 equiv) $\mathrm{Na}_{2} \mathrm{CO}_{3}$ ( 0.5 equiv)<smiles>S=P(c1ccccc1)(c1ccccc1)c1ccccc1</smiles>
$\frac{\begin{array}{c}\mathrm{S}(1 \text { equiv) } \\ \mathrm{Na}_{2} \mathrm{CO}_{3}(0.5 \text { equiv) }\end{array}}{\mathrm{TFE}, 90^{\circ} \mathrm{C} \text {, under air }} \mathrm{Ph}-\mathrm{Ph}_{\mathrm{Ph}}^{-} \mathrm{Ph}$

(Eq. 2)

1a

With $\mathrm{Ag}_{2} \mathrm{CO}_{3}, 91,51 \%$; Without $\mathrm{Ag}_{2} \mathrm{CO}_{3}$, no reaction<smiles>S=C(N1CCCCC1)N1CCCCC1</smiles>
$\mathrm{PdCl}_{2}\left(\mathrm{PPh}_{3}\right)_{2}$ (1 equiv) $\mathrm{Ag}_{2} \mathrm{CO}_{3,91}$, (1.5 equiv) $\mathrm{Na}_{2} \mathrm{CO}_{3}$ ( 0.5 equiv)

TFE, $90^{\circ} \mathrm{C}$, under air 9\% From recystallization

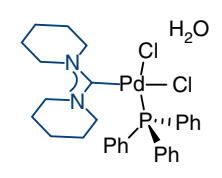
Neutral form 94 $30 \mathrm{~min}$
HRMS (ESI) $\mathrm{PPh}_{3}$

(Eq. 3)

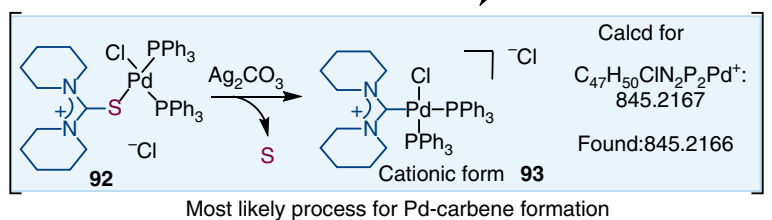<smiles>S=C(N1CCCCC1)N1CCCCC1</smiles>

$1 a$

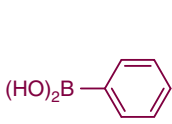

$2 a$

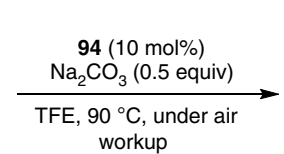

workup

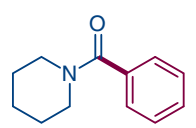

With $\mathrm{Ag}_{2} \mathrm{CO}_{3}$ 3, $75 \%$ Without $\mathrm{Ag}_{2} \mathrm{CO}_{3}$, no reaction<smiles></smiles>

94<smiles>O=Cc1ccccc1</smiles>

$2 a$<smiles>O=C(c1ccccc1)N1CCCCC1</smiles>

With $\mathrm{Ag}_{2} \mathrm{CO}_{3}, 3,81 \%$ Without $\mathrm{Ag}_{2} \mathrm{CO}_{3}, 3,70 \%$

(Eq. 4)

(Eq. 5)

c

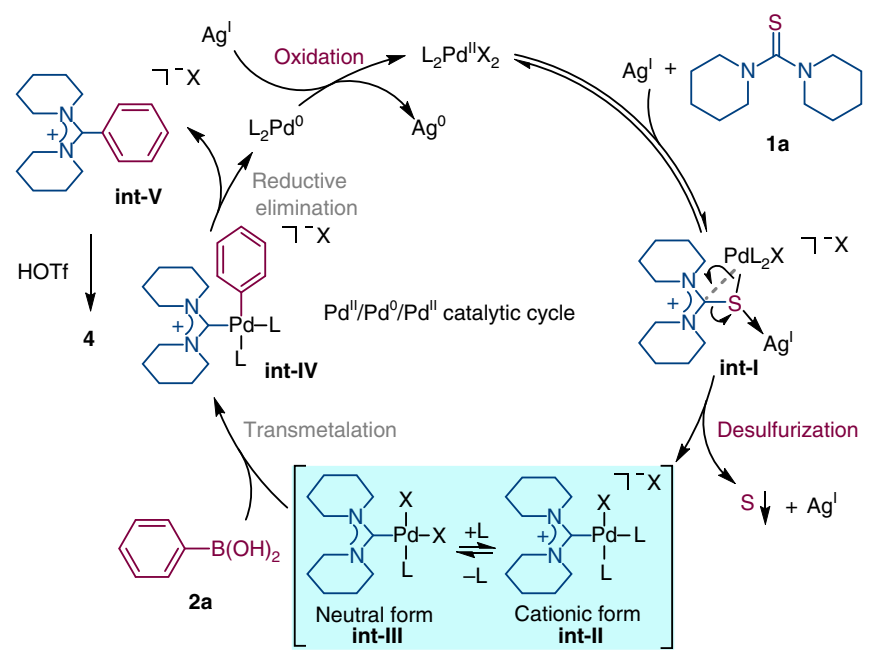

Fig. 4 Insights into the reaction mechanism. a Transformation of urea 90. b Mechanistic investigation. c The proposed mechanism.

reaction mechanism, the dependence of the initial rate on the concentrations of thiourea, $\mathrm{PhB}(\mathrm{OH})_{2}$ (2a), $\mathrm{PdCl}_{2}\left(\mathrm{PPh}_{3}\right)_{2}$ and $\mathrm{Ag}_{2} \mathrm{CO}_{3}$ were examined respectively (see Supplementary Figs. 6-13). Zero-order relationships of the initial rate with the concentration of thiourea and $\mathrm{PhB}(\mathrm{OH})_{2}$ were observed. A first-order dependence of the initial rate on the amount of the palladium catalyst was established. For $\mathrm{Ag}_{2} \mathrm{CO}_{3}$, there was an induction phase observed in initial rate-concentration plots. 
After the induction phase, the reaction is clearly first order in $\mathrm{Ag}_{2} \mathrm{CO}_{3}$.

Proposed mechanism. On the basis of the aforementioned results, a plausible mechanism, based on silver-facilitated $\mathrm{Pd}^{\mathrm{II}} /$ $\mathrm{Pd}^{0} / \mathrm{Pd}^{\mathrm{II}}$ catalytic cycle (for the possibility of heterogeneous $\mathrm{Pd}$ catalysis, see Supplementary Fig. 5), is depicted in Fig. 4. First, the reversible intermediate int-I is formed via coordination or complexation ${ }^{62,63}$ of $\mathrm{L}_{2} \mathrm{Pd}^{\mathrm{II}} \mathrm{X}_{2}$ with substrate (1a) in the presence of a silver salt ${ }^{25}$, which leads to $\mathrm{Ag}^{\mathrm{I}}$-facilitated desulfurization to produce the $\mathrm{Pd}^{\mathrm{II}}$-diaminocarbene intermediate along with the expulsion of sulfur and $\mathrm{Ag}^{\mathrm{I}}$ salt (or their complex). We consider that sulfur-extrusion reaction is similar to the decarbonylation ${ }^{64}$, desulfitation and decarboxylation ${ }^{65,66}$. Next, The intermediate is in equilibrium between the cationic form int-II and the neutral form int-III, which involves the displacement of ligand on intermediate int-II by the nucleophilic $\mathrm{X}^{-}$anion, yielding the neutral cis-form int-III ${ }^{22}$. With the presence of phenyl boronic acid (2a), the $\mathrm{Pd}^{\mathrm{II}}$-species int-IV is generated via the transmetalation. According to the related studies ${ }^{21,22}$ from Yates and Cavell, the $\mathrm{C}-\mathrm{C}$ bond formation of $\mathrm{Pd}^{\mathrm{II}}$-species int-IV could occur with a low activation barrier, proceeding via a concerted reductive elimination of the aryl and carbene moiety. Thus, the desired amidinium salt int- $\mathbf{V}$ is released through reductive elimination on $\mathrm{Pd}^{\mathrm{II}}$ center to $\mathrm{Pd}^{0}$ species; once again, the $\mathrm{Ag}^{\mathrm{I}}$ salt produced by desulfurization step would also serve as an oxidant to oxidize $\mathrm{Pd}^{0}$ to $\mathrm{Pd}^{\mathrm{II}}$ to furnish the catalytic cycle with the $\mathrm{Ag}^{0}$ (elemental silver) as by-product, which is consistent with the experimental results (Fig. 4c).

Further applications. With the development of the $\mathrm{Pd}$ catalyzed Suzuki-Miyaura coupling of thioureas and
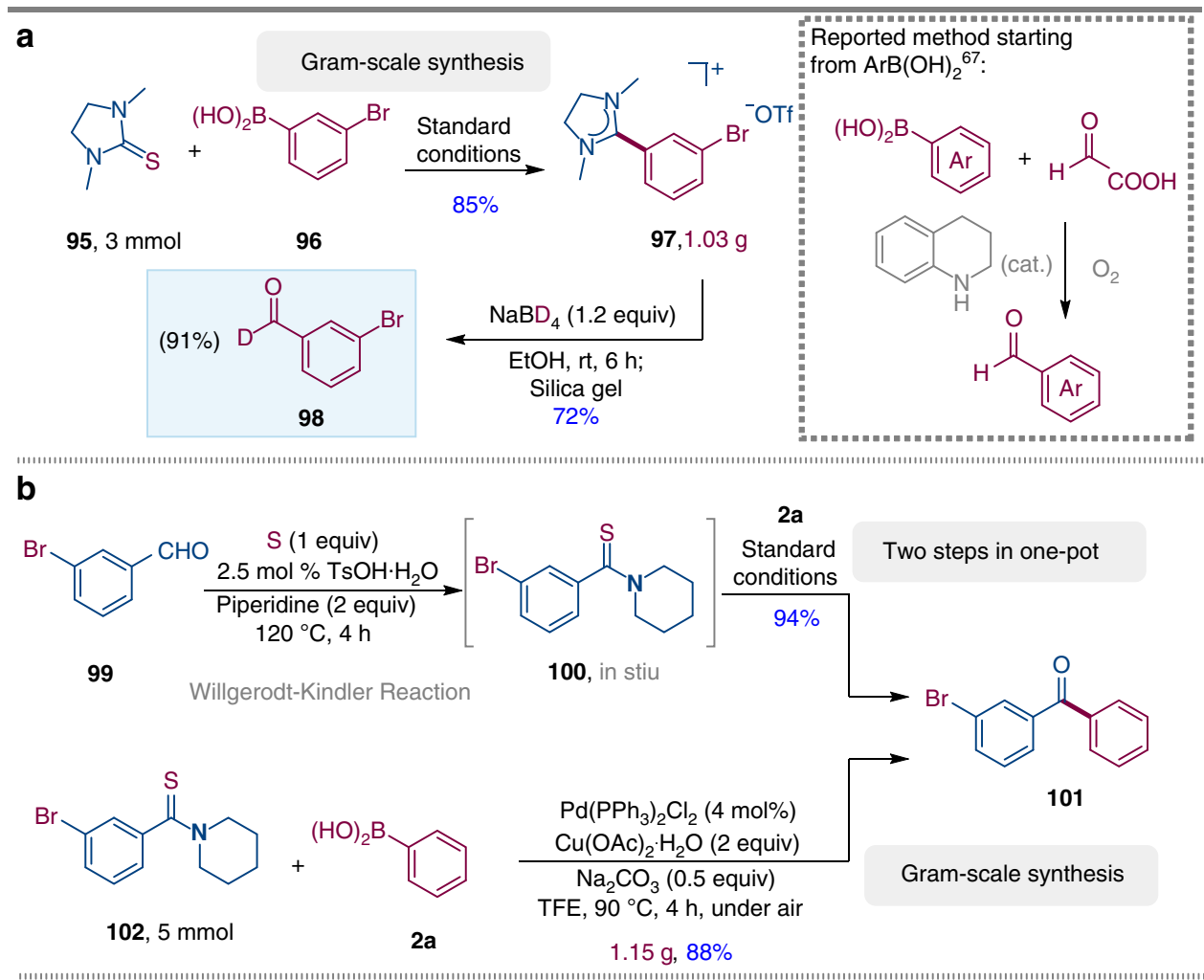

C<smiles>S=C(N1CCCCC1)N1CCCCC1</smiles>

1 a<smiles>O=Cc1ccc(Br)cc1</smiles>

$91 \%$<smiles>O=C(c1ccc(Br)cc1)N1CCCCC1</smiles>

104<smiles>S=C(c1ccc(Br)cc1)N1CCCCC1</smiles>

$95 \%$

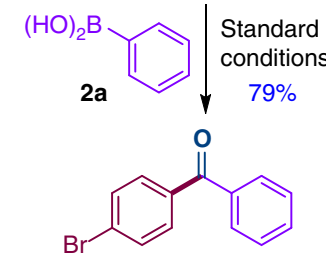

69

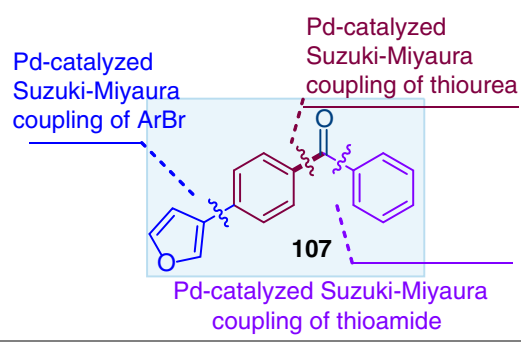

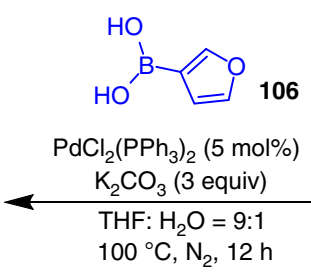

$86 \%$

coupling of thioamide

Fig. 5 Synthetic applications. a Concise synthesis of deuterated aldehyde $\mathbf{9 8}$. b One-pot synthesis of ketone $\mathbf{1 0 1}$ via Willgerodt-Kindler reaction and gramscale synthesis of ketone 101. c Orthogonal coupling for three different C-C bonds formation. 
thioamides, we decided to pursue their applications (Fig. 5). Firstly, A gram-scale version of the reaction using cyclic thiourea $95(3 \mathrm{mmol})$ and 3-bromophenylboronic acid 96 was performed, and the desired amidinium salt $\mathbf{9 7}$ was obtained in $85 \%$ yield on $1.03 \mathrm{~g}$ scale (Fig. $5 \mathrm{a}$ ). Next, deuterated aromatic aldehyde 98 ( $91 \%$ deuterated ratio) was obtained in $72 \%$ via the reduction of amidinium salt 97 using $\mathrm{NaBD}_{4}$ and subsequent hydrolysis. Very recently, the synthesis of aromatic aldehydes from arylboronic acids was firstly reported by Mariano and coworkes $^{67}$ via organocatalytic formylation reactions of boronic acids with glyoxylic acid. To the best of our knowledge, the synthesis of deuterated aromatic aldehydes from arylboronic acids, even if it takes two steps, has never been reported before, which leads to unique retrosynthetic relationship. To further demonstrate the practicability of our method, we have also developed a one-pot protocol starting directly from aldehydes. For example, 3-bromobenzaldehyde (99) could be converted to the corresponding thioamide via Willgerodt-Kindler reaction in one step $^{68}$, no further purification is required, 2a, Pd catalyst, $\mathrm{Cu}$ salt, $\mathrm{Na}_{2} \mathrm{CO}_{3}$ and TFE were added to the same reaction flask, and the corresponding cross-coupling product 101 was obtained in $94 \%$ yield in two steps after stirring the mixture at $90{ }^{\circ} \mathrm{C}$ for $4 \mathrm{~h}$ under air (Fig. 5b). A gram-scale version of the reaction using brominated substrates $\mathbf{1 0 2}$ and $2 \mathrm{a}$ was also carried out, and the desired ketone $\mathbf{1 0 1}$ was obtained in $88 \%$ yield on $1.15 \mathrm{~g}$ scale using only $4 \mathrm{~mol} \% \mathrm{PdCl}_{2}\left(\mathrm{PPh}_{3}\right)_{2}$ (Fig. 5b). Moreover, a sequential Pd-catalyzed Suzuki-Miyaura couplings starting from thiourea 1a was carried out in Fig. $5 \mathrm{c}$. Thiourea 1a was first coupled with para-bromo-phenylboronic acid 103, and amide 104 was obtained in 91\% yield, leaving bromo group untouched. Lawsson's reagent readily converted amide 104 into thioamide 105, which further underwent a Pd-catalyzed Suzuki-Miyaura coupling with phenylboronic acid 2a, rendering ketone 69 in $79 \%$ yield, once again, bromo group on aromatic ring was remained intact. A third Suzuki-Miyaura coupling between 69 and 3-furanylboronic acid 106 was performed, furnishing a ketone $\mathbf{1 0 7}$ in $86 \%$ yield. Therefore the combination of three Suzuki-Miyaura reactions provides the free design of ketones with three different $\mathrm{C}-\mathrm{C}$ bonds formation from the resource of boronic acids, while simple thiourea species donates a carbonyl bridge.

\section{Discussion}

In summary, we have reported a Suzuki-Miyaura coupling reaction of thioureas or thioamides to afford a broad array of substituted amidinium salts or valuable diaryl ketones. Inspired by the stoichiometric carbene-generating methods, we successfully realize the direct generation of metal-carbene complex in a catalytic manner. Single crystal structure of Pd-diaminocarbene complex is obtained and proven to be the key intermediate by both catalytic and stoichiometric reactions. Meanwhile, HRMS analysis further supports our hypothetical intermediates for reaction mechanism. Preliminary mechanistic studies demonstrate the dual roles of silver salt: (i) a desulfurating reagent that assist the elimination of sulfur; (ii) an oxidant that facilitate the $\mathrm{Pd}^{\mathrm{II}} / \mathrm{Pd}^{0} / \mathrm{Pd}^{\mathrm{II}}$ catalytic cycle. Further studies on expansion of this reaction to other substrates to achieve anothercoupling reactions as well as the development of this carbene chemistry are underway in our laboratory.

\section{Methods}

General procedure for the synthesis of amidinium salts. Thiourea $(0.2 \mathrm{mmol}$, 1.0 equiv), aryl boronic acid ( $0.4 \mathrm{mmol}, 2.0$ equiv), $\mathrm{PdCl}_{2}\left(\mathrm{PPh}_{3}\right)_{2}(14.0 \mathrm{mg}, 0.02$ mmol, $10 \mathrm{~mol} \%$ ), $\mathrm{Ag}_{2} \mathrm{CO}_{3}$ ( $82.7 \mathrm{mg}, 0.3 \mathrm{mmol}, 1.5$ equiv), $\mathrm{Na}_{2} \mathrm{CO}_{3}$ (10.6 mg, 0.1 mmol, 0.5 equiv), and TFE $(1.5 \mathrm{~mL})$, were placed in a $50 \mathrm{~mL}$ Schlenk sealed tube (with a Teflon cap) equipped with a magnetic stir bar. The reaction was stirred at $90^{\circ} \mathrm{C}$ for $4 \mathrm{~h}$ under air. Subsequently, the reaction mixture was cooled to room temperature and HOTf $(60 \mathrm{mg}, 0.4 \mathrm{mmol}, 2$ equiv) was added. The crude reaction mixture was concentrated in vacuo, and the residue was purified by flash chromatography on silica gel to provide the desired amidinium salts using $\mathrm{CH}_{2} \mathrm{Cl}_{2} /$ $\mathrm{MeOH}$ as the eluent.

General procedure for the synthesis of amide 3. Thiourea $(0.2 \mathrm{mmol}, 1.0$ equiv) aryl boronic acid ( $0.4 \mathrm{mmol}, 2.0$ equiv), $\mathrm{PdCl}_{2}\left(\mathrm{PPh}_{3}\right)_{2}(14.0 \mathrm{mg}, 0.02 \mathrm{mmol}, 10 \mathrm{~mol} \%)$ $\mathrm{Ag}_{2} \mathrm{CO}_{3}$ (82.7 mg, $0.3 \mathrm{mmol}, 1.5$ equiv), $\mathrm{Na}_{2} \mathrm{CO}_{3}$ ( $10.6 \mathrm{mg}, 0.1 \mathrm{mmol}, 0.5$ equiv), and TFE $(1.5 \mathrm{~mL})$, were placed in a $50 \mathrm{~mL}$ Schlenk sealed tube (with a Teflon cap) equipped with a magnetic stir bar. The reaction was stirred at $90^{\circ} \mathrm{C}$ for $4 \mathrm{~h}$ under air. Subsequently, the reaction mixture was cooled to room temperature and $1 \mathrm{M}$ $\mathrm{HCl}(10 \mathrm{~mL})$ was added. The mixture was then extracted with EtOAc. The organic layer was concentrated in vacuo, and the residue was purified by flash chromatography on silica gel to afford the amide 3 using petroleum ether/EtOAc as the eluent.

General procedure for the synthesis of diaryl ketones. Thioamide $(0.2 \mathrm{mmol}$, 1.0 equiv), aryl boronic acid $\left(0.4 \mathrm{mmol}, 2.0\right.$ equiv), $\mathrm{PdCl}_{2}\left(\mathrm{PPh}_{3}\right)_{2}(10.5 \mathrm{mg}, 0.015$ mmol, $7.5 \mathrm{~mol} \%$ ), $\mathrm{Cu}(\mathrm{OAc})_{2} \cdot \mathrm{H}_{2} \mathrm{O}$ (79.9 mg, $0.4 \mathrm{mmol}, 2$ equiv), $\mathrm{Na}_{2} \mathrm{CO}_{3}$ (10.6 mg, $0.1 \mathrm{mmol}, 0.5$ equiv), and TFE $(1.5 \mathrm{~mL})$, were placed in a $50 \mathrm{~mL}$ Schlenk sealed tube (with a Teflon cap) equipped with a magnetic stir bar. The reaction was stirred at $90^{\circ} \mathrm{C}$ for $4 \mathrm{~h}$ under air. Finally, the reaction mixture was cooled to room temperature and the crude reaction mixture was concentrated in vacuo. The remaining residue was purified by flash chromatography on silica gel to afford the diaryl ketones using petroleum ether/EtOAc as the eluent.

\section{Data availability}

Experimental procedures and characterization data are available within this article and its Supplementary Information. Data are also available from the corresponding author on request. The X-ray crystallographic coordinates for structures of $\mathbf{4}$ and $\mathbf{9 4}$ reported in this Article have been deposited at the Cambridge Crystallographic Data Centre (CCDC), under deposition numbers CCDC 1895265 and CCDC 1820330 respectively. These data can be obtained free of charge from The Cambridge Crystallographic Data Centre via http://www.ccdc.cam.ac.uk/data_request/cif.

Received: 5 July 2019; Accepted: 19 November 2019; Published online: 13 December 2019

\section{References}

1. Greenman, K. L., Carter, D. S. \& Van Vranken, D. L. Palladium-catalyzed insertion reactions of trimethylsilyldiazomethane. Tetrahedron 57, 5219-5225 (2001).

2. Barluenga, J., Moriel, P., Valdés, C. \& Aznar, F. N-tosylhydrazones as reagents for cross-coupling reactions: a route to polysubstituted olefins. Angew. Chem. Int. Ed. 46, 5587-5590 (2007).

3. Barluenga, J., Tomás-Gamasa, M., Aznar, F. \& Valdés, C. Metal-free carbon-carbon bond-forming reductive coupling between boronic acids and tosylhydrazones. Nat. Chem. 1, 494-499 (2009).

4. Barluenga, J. \& Valdés, C. Tosylhydrazones: new uses for classic reagents in palladium-catalyzed cross-coupling and metal-free reactions. Angew. Chem. Int. Ed. 50, 7486-7500 (2011).

5. Xia, Y. et al. Oxidative cross-coupling of allenyl ketones and organoboronic acids: expeditious synthesis of highly substituted furans. Angew. Chem. Int. Ed. 53, 3917-3921 (2014).

6. Xia, Y. et al. Palladium-catalyzed carbene migratory insertion using conjugated ene-yne-ketones as carbene precursors. J. Am. Chem. Soc. 135, 13502-13511 (2013)

7. Gao, Y., Wu, G., Zhou, Q. \& Wang, J. Palladium-catalyzed oxygenative crosscoupling of ynamides and benzyl bromides via carbene migratory insertion. Angew. Chem. Int. Ed. 57, 2716-2720 (2018).

8. Zhang, H. et al. Rhodium(III)-catalyzed transannulation of cyclopropenes with $\mathrm{N}$-phenoxyacetamides through $\mathrm{C}-\mathrm{H}$ activation. Angew. Chem. Int. Ed. 53, 13234-13238 (2014)

9. Wang, K., Ping, Y., Chang, T. \& Wang, J. Palladium-catalyzed [3+3] annulation of vinyl chromium $(0)$ carbene complexes through carbene migratory insertion/tsuji-trost reaction. Angew. Chem. Int. Ed. 56, 13140-13144 (2017).

10. Shao, Z. \& Zhang, H. N-Tosylhydrazones: versatile reagents for metalcatalyzed and metal-free cross-coupling reactions. Chem. Soc. Rev. 41, 560-572 (2012).

11. Xiao, Q., Zhang, Y. \& Wang, J. Diazo compounds and N-Tosylhydrazones: novel cross-coupling partners in transition-metal-catalyzed reactions. Acc. Chem. Res. 46, 236-572 (2013). 
12. Barroso, R., Cabal, M. P. \& Valdés, C. Pd-catalyzed auto-tandem cascades based on N-sulfonylhydrazones: hetero- and carbocyclization processes. Synthesis 49, 4434-4447 (2017).

13. Xia, Y., Qiu, D. \& Wang, J. Transition-metal-catalyzed cross-couplings through carbene migratory insertion. Chem. Rev. 117, 13810-13889 (2017).

14. Jia, M. \& Ma, S. New approaches to the synthesis of metal carbenes. Angew. Chem. Int. Ed. 55, 9134-2037 (2016).

15. Wang, K. \& Wang, J. Transition-metal-catalyzed cross-coupling with nondiazo carbene precursors. Synthesis 30, 542-551 (2017).

16. Kuhn, N. \& Kratz, T. Synthesis of imidazol-2-ylidenes by reduction of imidazole-2(3H)-thiones. Synthesis 1993, 561-562 (1993)

17. Hahn, F. E., Wittenbecher, L., Boese, R. \& Bläser, D. N, ff-Bis(2,2dimethylpropyl)benzimidazolin-2-ylidene: a stable nucleophilic carbene derived from benzimidazole. Chem. Eur. J. 5, 1931-1935 (1999).

18. Ansell, M. B., Roberts, D. E., Cloke, F. G. N., Navarro, O. \& Spencer, J. Synthesis of an $\left[(\mathrm{NHC})_{2} \mathrm{Pd}\left(\mathrm{SiMe}_{3}\right)_{2}\right]$ complex and catalytic cis-bis(silyl)ations of alkynes with unactivated disilanes. Angew. Chem. Int. Ed. 54, 5578-5582 (2015).

19. Li, J., Shi, L.-L., Chen, J., Gong, J. \& Yang, Z. Thioureas as ligands in organometallic reactions. Synthesis 46, 2007-2023 (2014)

20. Kremzow, D., Seidel, G., Lehmann, C. W. \& Fürstner, A. Diaminocarbeneand Fischer-carbene complexes of palladium and nickel by oxidative insertion: preparation, structure, and catalytic activity. Chem. Eur. J. 11, 1833-1853 (2005).

21. McGuinness, D. S., Green, M. J., Cavell, K. J., Skelton, B. W. \& White, A. H. Synthesis and reaction chemistry of mixed ligand methylpalladium-carbene complexes. J. Organomet. Chem. 565, 165-178 (1998).

22. McGuinness, D. S., Saendig, N., Yates, B. F. \& Cavell, K. J. Kinetic and density functional studies on alkyl-carbene elimination from pdii heterocylic carbene complexes: a new type of reductive elimination with clear implications for catalysis. J. Am. Chem. Soc. 123, 4029-4040 (2001).

23. Mai, S. \& Song, Q. Divergent synthesis of disulfanes and benzenesulfonothioates bearing 2-Aminofurans from $N$-tosylhydrazonebearing thiocarbamates. Angew. Chem. Int. Ed. 56, 7952-7957 (2017).

24. Li, W., Zhao, Y., Mai, S. \& Song, Q. Thiocarbamate-directed tandem olefination-intramolecular sulfuration of two ortho $\mathrm{C}-\mathrm{H}$ bonds: application to synthesis of a COX-2 Inhibitor. Org. Lett. 20, 1162-1166 (2018).

25. Avalos, M., Babiano, R., Duran, C. J., Jimenez, J. L. \& Palacios, J. C. Reaction of thioamides with silver carboxylates in aprotic media. A nucleophilic approach to the synthesis of imides, amides, and nitriles. Tetrahedron. Lett. 35, 477-480 (1994)

26. Ramana, T. \& Punniyamurthy, T. Preparation of 2-Azido-1-Substituted-1 HBenzo $[d]$ imidazoles using a copper-promoted three-component reaction and their further conversion into 2-Amino and 2-triazolyl derivatives. Chem. Eur. J. 18, 13279-13283 (2012)

27. Seelam, M., Shaikh, B. V., Tamminana, R. \& Kammela, P. R. An efficient methodology for the synthesis of thioureas from amine mediated by a cobalt source. Tetrahedron Lett. 57, 5297-5300 (2016).

28. Singh, C. B., Ghosh, H., Murru, S. \& Patel, B. K. Hypervalent Iodine(III) mediated regioselective $N$-Acylation of 1,3-disubstituted thioureas. J. Org. Chem. 73, 2924-2927 (2008).

29. Batey, R. A. \& Powell, D. A. A general synthetic method for the formation of substituted 5-Aminotetrazoles from thioureas: a strategy for diversity amplification. Org. Lett. 2, 3237-3240 (2000).

30. Liebeskind, L. S. \& Srogl, J. Thiol Ester-Boronic acid coupling. A mechanistically unprecedented and general ketone synthesis. J. Am. Chem. Soc. 122, 11260-11261 (2000).

31. Prokopcov, H. \& Kappe, C. The Liebeskind-Srogl C-C Cross-Coupling Reaction. Angew. Chem. Int. Ed. 48, 2276-2286 (2009).

32. Pan, F., Wang, H., Shen, P.-X., Zhao, J. \& Shi, Z.-J. Cross coupling of thioethers with aryl boroxines to construct biaryls via $\mathrm{Rh}$ catalyzed $\mathrm{C}-\mathrm{S}$ activation. Chem. Sci. 4, 1573-1577 (2013).

33. Ma, Y., Cammarata, J. \& Cornella, J. Ni-Catalyzed reductive Liebeskind-Srogl alkylation of heterocycles. J. Am. Chem. Soc. 141, 1918-1922 (2019).

34. Pan, F. \& Shi, Z.-J. Recent advances in transition-metal-catalyzed C-S activation: from thioester to (Hetero)aryl thioether. ACS Catal. 4, 280-288 (2014).

35. Modha, S. G., Mehta, V. P. \& Van der Eycken, E. V. Transition metalcatalyzed $\mathrm{C}-\mathrm{C}$ bond formation via $\mathrm{C}-\mathrm{S}$ bond cleavage: an overview. Chem. Soc. Rev. 42, 5042-5055 (2013).

36. Miyaura, N. \& Suzuki, A. Palladium-catalyzed cross-coupling reactions of organoboron compounds. Chem. Rev. 95, 2457-2483 (1995).

37. Han, F.-S. Transition-metal-catalyzed Suzuki-Miyaura cross-coupling reactions: a remarkable advance from palladium to nickel catalysts. Chem. Soc. Rev. 42, 5270-5298 (2013)

38. Muto, K., Yamaguchi, J., Musaev, D. G. \& Itami, K. Decarbonylative organoboron cross-coupling of esters by nickel catalysis. Nat. Commun. 6, 7508-7015 (2015).
39. Weires, N. A., Baker, E. L. \& Garg, N. K. Nickel-catalysed Suzuki-Miyaura coupling of amides. Nat. Chem. 8, 75-79 (2016).

40. Shi, S., Meng, G. \& Szostak, M. Synthesis of Biaryls through Nickel-Catalyzed Suzuki-Miyaura coupling of amides by carbon-nitrogen bond cleavage. Angew. Chem. Int. Ed. 55, 6959-6963 (2016).

41. Halima, T. B. et al. Palladium-catalyzed Suzuki-Miyaura coupling of aryl esters. J. Am. Chem. Soc. 139, 1311-1318 (2017).

42. Witzel, S. et al. Cross-coupling of boronic acids and diazonium salts enabled by visible light. Adv. Synth. Catal. 359, 1522-1528 (2017).

43. Malapit, C. A., Bour, J. R., Brigham, C. E. \& Sanford, M. S. Base-free nickelcatalysed decarbonylative Suzuki-Miyaura coupling of acid fluorides. Nature 563, 100-104 (2018).

44. Cao, Z.-C., Xie, S.-J., Fang, H. \& Shi, Z.-J. Ni-catalyzed cross-coupling of dimethyl aryl amines with arylboronic esters under reductive conditions. $J$ Am. Chem. Soc. 140, 13575-13579 (2018).

45. Turek, A. K., Hardee, D. J., Ullman, A. M., Nocera, D. G. \& Jacobsen, E. N. Activation of electron-deficient quinones through hydrogen-bond-donorcoupled electron transfer. Angew. Chem. Int. Ed. 55, 539-544 (2016).

46. Uesugi, T., Yanai, H. \& Soneta, Y. Metal-free antistatic agents having good transparency and compatibility with polymers and solvents, and their uses. JP 2010138234 A (2010).

47. Wright, A., Weissbach, G. T. \& Holdcroft, S. Poly(phenylene) and mTerphenyl as powerful protecting groups for the preparation of stable organic hydroxides. Angew. Chem. Int. Ed. 55, 4818-4821 (2016).

48. Kelley, C. et al. 3-Phenyl substituted 6,7-dimethoxyisoquinoline derivatives as FtsZ-targeting antibacterial agents. Bioorg. Med. Chem. 20, 7012-7029 (2012)

49. Welton, T. Room-temperature ionic liquids. Solvents for synthesis and catalysis. Chem. Rev. 99, 2071-2084 (1999).

50. Plechkova, N. V. \& Seddon, K. R. Applications of ionic liquids in the chemical industry. Chem. Soc. Rev. 37, 123-150 (2008).

51. Lee, C. W. \& Lee, J. Y. High quantum efficiency in solution and vacuum processed blue phosphorescent organic light emitting diodes using a novel benzofuropyridine-based bipolar host material. Adv. Mater. 25, 596-600 (2013).

52. Jue, S. G., Dawson, G. W. \& Brogden, R. N. Amoxapine: a review of its pharmacology and efficacy in depressed states. Drugs 24, 1-23 (1982).

53. Marrière, E., Rouden, J., Tadino, V. \& Lasne, M.-C. Synthesis of analogues of (-)-Cytisine for in vivo studies of nicotinic receptors using positron emission tomography. Org. Lett. 2, 1121-1124 (2000)

54. Jagodzinéski, T. S. Thioamides as useful synthons in the synthesis of heterocycles. Chem. Rev. 103, 197-228 (2003).

55. Ozturk, T., Ertas, E. \& Mert, O. Use of Lawesson's reagent in organic syntheses. Chem. Rev. 107, 5210-5278 (2007).

56. Priebbenow, L. D. \& Bolm, C. Recent advances in the Willgerodt-Kindler reaction. Chem. Soc. Rev. 42, 7870-7880 (2013).

57. Wei, J., Li, Y. \& Jiang, X. Aqueous compatible protocol to both alkyl and aryl thioamide synthesis. Org. Lett. 18, 340-343 (2016).

58. Nahm, S. \& Weinreb, S. M. N-Methoxy- $N$-methylamides as effective acylating agents. Tetrahedron Lett. 22, 3815-3818 (1981).

59. Milstein, D. \& Stille, J. K. A general, selective, and facile method for ketone synthesis from acid chlorides and organotin compounds catalyzed by palladium. J. Am. Chem. Soc. 100, 3636-3638 (1978).

60. Hu, L. et al. Novel potent antimitotic heterocyclic ketones: synthesis antiproliferative activity, and structure-activity relationships. Bioorg. Med. Chem. Lett. 17, 3613-3617 (2007).

61. McGrath, N. A., Brichacek, M. \& Njardarson, J. T. A graphical journey of innovative organic architectures that have improved our lives. J. Chem. Educ. 87, 1348-1349 (2010)

62. Xiao, Q. et al. Direct imidation to construct $1 H$-Benzo[d]imidazole through $\mathrm{Pd}^{\mathrm{II}}$-Catalyzed $\mathrm{C}-\mathrm{H}$ activation promoted by thiourea. Chem. Eur. J. 15, 7292-7296 (2009).

63. Slivarichova, M., Reading, E., Mairi Haddow, F., Othman, H. \& Owen, G. R Silver and palladium complexes containing ditopic N-heterocyclic carbene-thione ligands. Organometallics 31, 6595-6607 (2012).

64. Somerville, R. J. \& Martin, R. Forging C-C bonds through decarbonylation of aryl ketones. Angew. Chem. Int. Ed. 56, 6708-6710 (2017).

65. Liu, B., Guo, Q., Cheng, Y., Lan, J. \& You, J. Palladium-catalyzed desulfitative $\mathrm{C}-\mathrm{H}$ arylation of heteroarenes with sodium sulfinates. Chem. Eur. J. 17, 13415-13419 (2011)

66. Li, H., Miao, T., Wang, M., Li, P. \& Wang, L. Recent advances in exploring diverse decarbonylation, decarboxylation and desulfitation coupling reactions for organic transformations. Synlett 27, 1635-1648 (2016).

67. Huang, H. et al. Synthesis of aldehydes by organocatalytic formylation reactions of boronic acids with glyoxylic acid. Angew. Chem. Int. Ed. 56 8201-8205 (2017)

68. Koduri, N. D. et al. Ruthenium catalyzed synthesis of enaminones. Org. Lett. 14, 440-443 (2012). 


\section{Acknowledgements}

Financial support from the National Natural Science Foundation (21772046) and the Natural Science Foundation of Fujian Province (2016J01064) are gratefully acknowledged. We also thank Instrumental Analysis Center of Huaqiao University for analysis support. S.M. thanks the Subsidized Project for Cultivating Postgraduates' Innovative Ability in Scientific Research of Huaqiao University.

\section{Author contributions}

Q.S. conceived and designed the experiments. S.M. and W.L. performed experiments and prepared the Supplementary Information. X.L. and Y.Z. helped collecting some new compounds. Q.S. and S.M. wrote the paper. S.M. and W.L. contributed equally to this work. All authors discussed the results and commented on the manuscript.

\section{Competing interests}

The authors declare no competing interests.

\section{Additional information}

Supplementary information is available for this paper at https://doi.org/10.1038/s41467019-13701-5.

Correspondence and requests for materials should be addressed to Q.S.
Peer review information Nature Communications thanks Zhangjie Shi and the other, anonymous, reviewer(s) for their contribution to the peer review of this work.

Reprints and permission information is available at http://www.nature.com/reprints

Publisher's note Springer Nature remains neutral with regard to jurisdictional claims in published maps and institutional affiliations.

\section{cc) (i)}

Open Access This article is licensed under a Creative Commons Attribution 4.0 International License, which permits use, sharing, adaptation, distribution and reproduction in any medium or format, as long as you give appropriate credit to the original author(s) and the source, provide a link to the Creative Commons license, and indicate if changes were made. The images or other third party material in this article are included in the article's Creative Commons license, unless indicated otherwise in a credit line to the material. If material is not included in the article's Creative Commons license and your intended use is not permitted by statutory regulation or exceeds the permitted use, you will need to obtain permission directly from the copyright holder. To view a copy of this license, visit http://creativecommons.org/licenses/by/4.0/.

(C) The Author(s) 2019 